\title{
Arthur Schopenhauer e a Tradição Jusnaturalista Moderna
}

\author{
Felipe dos Santos Durante \\ Mestrando em Filosofia pela UNICAMP/Bolsista da FAPESP
}

RESUMO: Este artigo tem como objetivo examinar a relação da doutrina do direito de Arthur Schopenhauer com a tradição conhecida por jusnaturalismo moderno. Para tanto, o artigo foi dividido em duas sessões: (i) a exposição da definição, em linhas gerais, do que se entende por tradição jusnaturalista moderna, e (ii) a relação de Schopenhauer com essa tradição.

PALAVRAS-CHAVE: Jusnaturalismo, Direito Natural, Ética.

ABSTRACT: This article aims to show the relationship between Arthur Schopenhauer's doctrine of rights and the modern jusnaturalism tradition. For this purpose the article was divided in two sections: (i) an exposition in general lines about what we understand for modern jusnaturalism tradition, and (ii) the relationship between Schopenhauer and this tradition.

KEYWORDS: Jusnaturalism, Natural Rights, Ethics.

\section{Jusnaturalismo ou a Escola do Direito Natural}

Arthur Schopenhauer (1788-1860), ${ }^{1}$ ao formular suas teorias do direito e do Estado, faz um "acerto de contas" com certas teorias em voga, notadamente com autores que pertencem a um determinado período da história da filosofia, denominado pelos estudiosos por período moderno. Durante esse período, jusnaturalismo moderno e história da filosofia do direito foram em boa medida confundidos, tanto que por muitos séculos a disciplina de filosofia do direito foi designada por jus naturae ou jus naturale ${ }^{2}$. Como este artigo não tem a pretensão de realizar uma investigação exaustiva e pormenorizada de cada autor do período em questão, examinando a especificidade de cada um deles com vistas a assimilar

\footnotetext{
${ }^{1}$ Adotou-se a edição das obras completas em alemão organizadas por Paul Deussen: SCHOPENHAUER, A. Arthur Schopenhauers sämtliche Werke; hrsg. Von Paul Deussen. Munique: R. Piper, 1911-1942. A tradução adotada de Die Welt als Wille und Vorstellung para uma leitura cotejada com a obra em idioma alemão foi feita por Jair Lopes Barboza: $O$ mundo como vontade e como representação, $1^{\circ}$ Tomo; São Paulo: Editora UNESP, 2005. Doravante abreviado como $M V R I$, seguido da indicação de parágrafo e página, e do tomo e da paginação em referência à edição alemã.

Para o segundo volume de $M V R$ adotaram-se duas traduções para leitura cotejada com o original: (i) The world as will and representation, $2^{\circ}$ Tomo; Tradução E.F.J. Payne. Nova York: Dover Publications, 1966; e (ii) El mundo como voluntad y representación, $2^{\circ}$ Tomo (complementos); introdução, tradução e notas de Pilar López de Santa Maria. In: Coleção Clássicos de la Cultura; Madri: Editorial Trotta SA, 2005. Doravante, faz-se referência ao segundo tomo d'O mundo como vontade e como representação por MVR II, seguida da indicação de página nas edições espanhola, inglesa e alemã. Quando necessidade de citação de $M V R I I$, a tradução para o português será de minha autoria, a partir do idioma alemão, salvo indicação contrária. Após cada citação, serão apresentados em nota de rodapé os excertos utilizados em seu idioma original.

${ }^{2}$ Cf. BARRETO, V. Dicionário de filosofia do direito, p.240, verbete Direito natural.
} 
todas as semelhanças e dessemelhanças de suas teorias a fim de fazer a reconstituição mais completa possível do período, mas sim o de uma explicitação das principais características desse período assimiladas e reinterpretadas pelo filósofo da Vontade, foi necessário delimitar um escopo de investigação mínimo - mas que pudesse evidenciar os aspectos desejados.

Em primeiro lugar é preciso explicitar o modo de procedimento pelo qual os teóricos partidários do direito natural no período em questão justificavam-no e fundamentavam-no, e qual o seu significado, embora uma definição precisa e incontestável seja impossível de ser enunciada - tamanho é o debate e a divergência entre os historiadores da filosofia. O que é possível fazer é evidenciar afinidades entre as teorias de um conjunto selecionado de teóricos analisados e comentadores, visando estabelecer um estatuto teórico que permita afirmar que as teorias jusnaturalistas no período moderno compartilham de características basilares, características essas que possibilitam classificá-las sob tais rubricas, a fim de evidenciar uma certa maneira de proceder e uma certa estrutura e arquitetônica dos autores da escola do direito natural.

Pode-se afirmar que o direito natural, i.e., o conjunto de direitos inatos que independem de validação ou sanção, que subsistem independentemente de sua legalidade ou não - da consonância ou não com a lei posta, com o direito positivo -, do qual o homem é portador enquanto indivíduo singular, reúne algumas características, tais como: (i) a universalidade, uma vez que ele vale de igual modo para todos os indivíduos, ou seja, é o mesmo em todas as épocas e lugares; (ii) a imutabilidade, i.e., ele não se modifica em decorrência de alterações espaço-temporais; (iii) ser um parâmetro valorativo para o direito positivo; e (iv) ser válido em si e por si $^{3}$.

Durante o desenrolar da história dos homens, o fundamento do direito natural foi procurado por diferentes vias. Na antiguidade, o fundamento do direito natural era buscado no ordenamento da natureza, em um tipo de formulação que pode ser denominada de cosmológica. Durante o período medieval, os fundamentos do direito natural possuíam sua base na teologia, i.e., advinham da palavra e dos mandamentos de Deus. O jurista holandês

\footnotetext{
${ }^{3}$ BOBBIO, N. O positivismo jurídico: lições de filosofia do direito, p.22-23; Cf. REALE, M. Lições preliminares de direito, p.312; Cf. BARRETO, V. Dicionário de filosofia do direito, p.241, verbete Direito natural.
} 
Hugo Grotius (1583-1645), ${ }^{4}$ marca a transição da forma pela qual se procedia: o homem passa a figurar como centro e axioma da argumentação empreendida, e em decorrência dessa nova maneira de proceder, o direito natural passa, então, a ser pautado na natureza do homem. Essa metodologia para fundamentação do direito natural foi definido por muitos comentadores como sendo um método antropológico, laico e racional ${ }^{5}$. Assim, a partir da descrição da natureza do homem, o conceito de direito natural poderia ser extraído e definido, dando suporte à fundamentação das leis e do Estado.

\section{A relação de Schopenhauer com o Jusnaturalismo Moderno}

A partir do breve recorte do que se julgou pertinente para esta exposição acerca da significação do jusnaturalismo moderno, pode-se tentar entender a forma como Schopenhauer mobilizou elementos dessa tradição na formulação de suas doutrinas do direito e do Estado.

A argumentação de Schopenhauer parte do conceito originário e positivo de injustiça (Unrecht), ${ }^{6}$ que é derivado diretamente do conceito de egoísmo (Egoismus). As conexões que Schopenhauer traça entre egoísmo e injustiça indicam que o egoísmo não é somente uma motivação indiferente ou neutra, mas está necessariamente conectado com a origem da guerra de todos contra todos. No início do $\S 62$ de MVR I, Schopenhauer escreve:

Já examinamos a primeira e a mais simples afirmação da Vontade de vida, a simples afirmação do próprio corpo, vale dizer, a exposição da Vontade via atos no tempo, na medida em que o corpo, em sua forma e finalidade, expõe essa mesma Vontade espacialmente, e não mais. Semelhante afirmação se mostra como conservação do corpo por meio do emprego de suas forças? ${ }^{7}$.

\footnotetext{
4 Hugo Grotius (também conhecido por Huig de Groot, Ugo Grozio, e Hugo Grocius, dependendo das variações lingüísticas e da tradução adotada para o seu nome) nasceu em Delft (Holanda). Nascido em uma época impregnada de valores humanistas, calvinistas e aristotélicos, foi educado no auge da influência do protestantismo e do aristotelismo (Cf. TUCK, R. Natural rights theories: their origin and development, p.58.). Aos doze anos já era considerado um milagre intelectual, graduando-se em direito com quinze anos. Foi professor de retórica em Leiden, tradutor, poeta, historiador, e diplomata - trabalhando em diversos governos, como os governos da Holanda, e da Suécia. Suas principais obras são De iure belli ac pacis, De iure praedae, e De iure sumarim potestatum circa sacia.

${ }^{5}$ Cf. HÖFFE, O. Estudios sobre teoria del derecho y la justiça, p.9; Cf. GOYARD-FABRE, S. Os fundamentos da ordem jurídica, p.XX-XXX; Cf. REALE, M. Filosofia do direito p.644-645; Cf. BARRETO, V. Dicionário de filosofia do direito, p.241, verbete Direito natural.

${ }^{6}$ Cf. MVR I, §62, p. 434, I 399.
} 

completa:

E, no sentido do egoísmo consistir na afirmação do próprio corpo, Schopenhauer

- Ora, na medida em que a Vontade expõe aquela AUTO-AFIRMAÇÃO do próprio corpo em inumeráveis indivíduos, um ao lado do outro, essa autoafirmação, em virtude do egoísmo inerente a todos, vai muito facilmente além de si mesma até a NEGAÇÃO da mesma Vontade que aparece em outro indivíduo ${ }^{8}$.

O egoísmo pode levar à invasão dos limites da afirmação da vontade alheia. Essa invasão pode ocorrer por (i) ferimento, (ii) por destruição do corpo de outrem ou (iii) quando ocorre a imposição de uma vontade particular a uma vontade alheia - que é negada e passa, então, a servir à vontade impositiva. ${ }^{9}$ Esta afirmação da vontade para além do próprio corpo, mediante a negação da vontade de outrem, é definida por Schopenhauer como injustiça (Unrecht). Quem sofre injustiça - quem tem a vontade negada por uma vontade estranha sente esta invasão na esfera de afirmação do próprio corpo - a primeira e mais básica afirmação da Vontade de vida (Wille zu Leben).

Todavia, a injustiça também se manifesta no ataque à propriedade (Eigentum) alheia, cuja definição é enunciada de forma genérica como aquilo que foi trabalhado por intermédio das próprias forças. ${ }^{10}$ De acordo com essa definição, o trabalho do corpo alheio e a propriedade confundem-se e identificam-se, fazendo com que o ato de atacar um corpo sem vida, i.e., o ato de atacar uma propriedade identificada com um corpo alheio, também seja injustiça ${ }^{11}$. Dessa maneira, quem usurpa uma propriedade serve-se das forças do corpo, da vontade ali objetivada, a fim de fazê-las servir à vontade objetivada no corpo usurpador. Para Schopenhauer, todo autêntico direito de propriedade é um direito moralmente fundamentado e está originariamente baseado única e exclusivamente no trabalho elaborador.

\footnotetext{
${ }^{7}$ MVR I, §62, p.428, I 393-394. No original: „Es ist bereits auseinandergesetzt, daß die erste und einfache Bejahung des Willens zum Leben nur Bejahung des eigenen Leibes ist, d.h. Darstellung des Willens durch Akte in der Zeit, in so weit schon der Leib, in seiner Form und Zweckmäßigkeit, denselben Willen räumlich darstellt, und nicht weiter. Diese Bejahung zeigt sich als Erhaltung des Leibes, mittelst Anwendung der eigenen Kräfte desselben“".

${ }^{8}$ MVR I, §62, p.429, I 394. No original: „—- Indem nun aber der Wille jene Selbstbejahung des eigenen Leibes in unzähligen Individuen neben einander darstellt, geht er, vermöge des Allen eigenthümlichen Egoismus, sehr leicht in einem Individuo über diese Bejahung hinaus, bis zur Verneinung desselben, im andern Individuo erscheinenden Willens“.

${ }^{9}$ Cf. MVR I, §62, p.429, I 394.

${ }^{10}$ Cf. MVR I, §62, p.430, I 396.

${ }^{11}$ Em suma, atacar uma propriedade identificada com o corpo de outrem equivale a atacar esse mesmo ser.
} 
O conceito caracterizado por ser derivado e negativo, i.e., o conceito oposto ao de injustiça, é justamente o conceito de justiça (Recht). Esse pode ser definido como mera negação do conceito de injustiça, visto que, segundo Schopenhauer, não seria cunhado o conceito de justiça se não houvesse a injustiça. Assim, a injustiça é a condição de existência da justiça; e esta é toda ação praticada que não seja a negação da vontade alheia por uma vontade estranha àquela. Será classificada (subsumiert) como justa toda ação que não ultrapasse o limite exposto, ou seja, toda ação que não seja negação da vontade alheia em favor da mais forte afirmação da vontade. O limite existente entre afirmar a própria vontade e o negar a de outrem fornece, em referência a uma simples e pura determinação moral, todo o domínio das possíveis ações injustas ou justas.

Delimitados os conceitos e os limites da injustiça e da justiça, Schopenhauer pode, agora, iniciar a sua argumentação acerca do conceito de direito. Esta transição tem como ponto de partida o seguinte argumento:

O conceito de JUSTIÇA, como negação da injustiça, encontra sua principal aplicação, e sem dúvida sua primeira origem, nos casos em que uma tentada injustiça por violência é impedida. Ora, como uma tal defesa não pode ser uma injustiça, conseqüentemente é justa, embora o ato de violência ali praticado, considerando em si e isoladamente, seja injustiça, no entanto aqui justificado por seu motivo, isto é, converte-se em direito ${ }^{12}$.

É possível afirmar que a ação de defender-se de uma injustiça - negar a imposição de uma vontade exterior à vontade própria do indivíduo -, ao ser justificado por um motivo, torna-se um direito. $\mathrm{O}$ indivíduo que sofre a injustiça tem o direito de negar a negação de vontade imposta a ele com a força necessária para suprimi-la ${ }^{13}$. Tem-se dessa forma um direito de coação (Zwangsrecht) baseado no seguinte raciocínio: se uma vontade estranha ao indivíduo tenta negar a vontade dele, ele pode usar suas forças para se conservar e sem injustiça (ohne Unrecht) exercer uma coação (Zwang) sobre aquela vontade estranha. Esta coação visa à desistência da negação de vontade a ser imposta, sem que isso negue a vontade impositiva, que se mantém em seu limite.

\footnotetext{
${ }^{12}$ MVR I, §62, p. 435, I 400. No original: „Der Begriff des Rechts, als der Negation des Unrechts, hat aber seine hauptsächliche Anwendung, und ohne Zweifel auch seine erste Entstehung, gefunden in den Fällen, wo versuchtes Unrecht durch Gewalt abgewehrt wird, welche Abwehrung nicht selbst wieder Unrecht seyn kann, folglich Recht ist; obgleich die dabei ausgeübte Gewaltthätigkeit, bloß an sich und abgerissen betrachtet, Unrecht wäre, und hier nur durch ihr Motiv gerechtfertigt, d.h. zum Recht wird“".

${ }^{13}$ Isto é, ele tem o direito de afirmar a própria vontade sobre a vontade estranha.
} 
Schopenhauer investigou o egoísmo e observou que este tem como essência a auto-afirmação, e que esta pode extrapolar os seus próprios limites, e invadir a esfera da afirmação da Vontade de vida no corpo alheio. Esta invasão da vontade do outro foi denominada injustiça e, após a pormenorização deste conceito, pela sua negação, definiu-se o conceito de justiça. Estes dois termos - injustiça e justiça - podem ser considerados determinações morais, uma vez que se referem à conduta humana enquanto tal, e à íntima significação dessa conduta em si (die innere Bedeutung dieses Handelns an sich) ${ }^{14}$.

Por serem determinações morais, os direitos derivados dos conceitos de injusto e justo podem ser denominados naturais, no sentido de que não estão definidos por convenções humanas nem são instituídos pelo Estado, mas existem de maneira inata valem por si e em si -, e são universais e imutáveis - pois valem para todos os indivíduos, em qualquer localidade, e em qualquer época.

Essa significação da conduta humana em si constitui a fundação e o conteúdo do Direito Natural (Naturrecht) e, desse modo, é anterior à instituição do Estado. Logo, essa significação fornecida pela doutrina do direito, através dos conceitos de injustiça e de justiça, existiria inclusive no estado de natureza, à margem de qualquer lei positiva. Contudo, no estado de natureza, a validade do direito moral não se dá em todos os casos para cada indivíduo, permanecendo latente - um direito que não se efetiva -, e, assim, não é eficaz no sentido de impedir que a violência impere. Nesse sentido, como argumenta Schopenhauer, os conceitos de justiça e de injustiça são de fato válidos para o estado de natureza, mas valem ali apenas como conceitos morais para o autoconhecimento, para a consciência moral da vontade de cada um. Pode-se atentar para o que Schopenhauer escreve:

Essa significação puramente moral é a única que a justiça e a injustiça têm para os homens enquanto homens, não como cidadãos do Estado, e que, portanto, subsistiria inclusive no estado de natureza, sem lei positiva ${ }^{15}$.

\footnotetext{
${ }^{14}$ Cf. MVR I, §62, p. 436, I 402.

${ }^{15}$ MVR I, §62, p.437, I 403. No original: „Diese rein moralische Bedeutung ist die einzige, welche Recht und Unrecht für den Menschen als Menschen, nicht als Staatsbürger haben, die folglich auch im Naturzustande, ohne alles positive Gesetz[...]“".

Nota-se neste excerto a primeira inversão na ordem dos termos: injustiça e justiça, empregados até então sempre nessa ordem, para justiça e injustiça.
} 
Para Schopenhauer, o direito natural poderia melhor ser denominado direito moral, pois sua validade se estende apenas ao ato e ao autoconhecimento originário desse ato de vontade individual, que se chama consciência moral (Gewissen). Assim, neste ponto, além de ser possível observar as assimilações que Schopenhauer faz da tradição, é possível notar a subsunção que ele efetua do direito à moral.

É importante salientar que a moral tem como escopo de investigação o agir, e não o sofrer; o agir é a exteriorização da vontade e, pelo fato da doutrina do direito ser parte da moral, por restrição, não pode considerar o sofrer. A partir desses elementos, Schopenhauer conclui que a doutrina do direito, além de ser uma parte contida na moral, se refere ao feito (Tun), não ao sofrer (Leiden). Este só é considerado pela moral indiretamente, tendo em vista provar que aquilo que se faz com o único fito de evitar o sofrimento de uma injustiça de modo algum é prática de injustiça.

Segundo Schopenhauer, o ato de praticar injustiça causa prazer no praticante. A razão reconhece que tanto para diminuir o sofrimento em toda parte quanto para reparti-lo da maneira mais justa possível, o melhor e o único meio é o de poupar a todos da dor relacionada ao sofrimento da injustiça, fazendo-lhes renunciar ao prazer obtido com a sua prática. Este meio possível é o contrato de Estado (Staatsvertrag) ou lei (Gesetz). O contrato que origina o Estado fornece ao cidadão a segurança de sua vida, de sua liberdade, de sua propriedade; esse (cidadão) deu como penhor sua vida e propriedade em favor da segurança de cada um. Assim, a razão faz o indivíduo abandonar seu prazer de praticar a injustiça para, então, poder ser protegido: o monopólio da injustiça, agora, pertence à instituição política instaurada. Logo, o Estado (Staat) passa a existir mediante um acordo comum $^{16}$.

Após explicitar qual a origem do Estado, e estabelecer a doutrina do direito como sendo moral, Schopenhauer argumenta que, ao contrário da moral que tem como objeto de investigação o agir, i.e., a conduta humana, e se restringe ao feito (Tun) da injustiça ou da justiça, a ciência política - ou teoria da legislação - tem por objeto de análise o sofrer (Leiden) injustiça. Moral e teoria da legislação convergem na medida em que a prática da injustiça e o sofrer injustiça relacionam-se mutuamente, constituindo uma correlação. Se fosse possível pensar uma prática de injustiça separada do sofrimento de injustiça pela

\footnotetext{
${ }^{16}$ Schopenhauer já escrevera, sob este aspecto, que o Estado é uma comunidade regida por convenção. Cf.
} MVR I, §62, p.432, I 397. 
outra parte, então, o Estado, enquanto instituição política, não poderia proibir-la. A proibição é feita a partir do momento em que há sofrimento de injustiça por uma das partes.

Ao Estado resta apenas o ato (Tat) como escopo de investigação, na medida em que há uma relação de reciprocidade entre esse e o sofrimento do outro. A disposição íntima, a intenção, é investigada apenas na proporção em que, a partir dela, conhece-se a significação do ato. Logo, pode-se afirmar que o Estado não proíbe ninguém de querer ou de desejar matar o próximo, desde que ele saiba com certeza que o medo da punição inibirá qualquer ação que concretize estes atos.

Com o objetivo de evitar as ações criminais - o ato de injustiça e seu correlato, o sofrer injustiça - a ciência política, ou legislação, empresta da moral a doutrina do direito, que determina os limites entre justiça e injustiça, para poder utilizar-se do reverso (Kehrseite) destes limites estabelecidos. Ou seja, estabelecidos os extremos do injusto e do justo (quais sejam: o injusto se configura pela invasão da esfera de afirmação da vontade no corpo alheio e que o justo é a negação do conceito de injustiça), invertem-se a perspectiva e a ordem dos valores: a legislação vigorará de acordo com o limite do justo estabelecido, que não pode ser transgredido. A argumentação de Schopenhauer conclui que a pura doutrina do direito, ou direito natural, que melhor se denominaria direito moral, ${ }^{17}$ é a base, embora sempre ao reverso (Kehrseite), de toda justa legislação positiva. Tem-se, neste ponto da argumentação, a clara determinação do direito natural como parâmetro valorativo para o direito positivo, como é possível observar na letra do filósofo:

A legislação, como dissemos, toma de empréstimo à moral a pura doutrina do direito, ou doutrina da natureza e dos limites do que é justo e injusto a fim de a aplicar ao inverso para fins próprios, alheios à moral, e assim instituir uma legislação positiva e os meios para mantê-la, ou seja, o Estado. A legislação positiva, portanto, é a pura doutrina do direito aplicada ao inverso ${ }^{18}$.

\subsection{O Direito Natural como Direito Internacional e Direito de Resistência}

\footnotetext{
${ }^{17}$ Schopenhauer, como visto, estabeleceu a equivalência destes três termos.

${ }^{18}$ MVR I, §62, p.443, I 409. O termo pura doutrina do direito é intercambiável por direito moral e direito natural.
} 
O Estado concebido por Schopenhauer surge para conveniência dos indivíduos, não possuindo nenhuma significação moral. Ele tem por obrigação o cumprimento de três finalidades básicas, que são expostas, de maneira breve, no capítulo 47 de MVR II (Zur Ethik - Sobre a Ética). O filósofo inicia sua argumentação acerca desta temática defendendo a tese de que os que negam a existência de um direito fora do Estado, os que negam o direito natural, confundem o direito com os meios de fazê-lo efetivar-se: isto é exatamente o que é o Estado. Só nele se torna assegurada a proteção do direito, mas esse (direito) existe independentemente daquele (Estado).

O Estado tem, segundo Schopenhauer, três deveres que se relacionam estritamente com a proteção, a saber, a (i) proteção a atos exteriores, a (ii) proteção interior e a (iii) proteção contra o protetor. ${ }^{19}$ Portanto, segundo Schopenhauer, quem pretende atribuir ao Estado outro fim que a proteção, desvia-o de sua verdadeira finalidade. Qualquer outra função que o Estado venha a exercer violará os próprios direitos dos cidadãos. O Estado deve, assim, ser mínimo, restringindo-se aos limites de seu papel negativo, indispensável para conter as desvantagens do egoísmo.

A proteção a atos exteriores tem como princípio fundamental a defesa, principalmente contra o ataque de outros povos, reconhecendo o direito internacional (Völkerrecht) - que para Schopenhauer "não passa do direito natural levado à esfera de sua atividade prática, a relação entre os povos" ${ }^{20}$. A proteção interior é responsável pela preservação dos membros do Estado entre si, garantindo o direito privado (Privatrechts), mediante o cumprimento da legislação, em um estado de direito (rechtlichen Zustandes).

$\mathrm{O}$ asseguramento dessas duas finalidades, dessas duas proteções, cria a necessidade de uma terceira proteção: a proteção contra o protetor, que é basicamente a defesa contra aquele ou aqueles aos quais a sociedade delegou o exercício da proteção e a tutela do Estado. É uma proteção que, utilizando como parâmetro o direito natural, assegura aos indivíduos o direito de resistência contra aqueles que o tutelam. Essa proteção garante o

\footnotetext{
${ }^{19}$ Cf. MVR II, cap. 47, p.651 (edição espanhola), p. 594-595 (edição inglesa), II 681.

${ }^{20}$ MVR II, cap. 47, p.651 (edição espanhola), p. 595 (edição inglesa), II 681. Esta passagem, na íntegra, no idioma original: „Dieses ist im Grunde nichts Anderes, als das Naturrecht, auf dem ihm allein gebliebenen Gebiet seiner praktischen Wirksamkeit, nämlich zwischen Volk und Volk, als wo es allein walten muß, weil sein stärkerer Sohn, das positive Recht, da es eines Richters und Vollstreckers bedarf, nicht sich geltend machen kann“.
} 
direito público (öffentlichen Rechtes), que é mais efetivo quando dividido em três poderes protetores, a saber, em poder legislativo, em poder judiciário, e em poder executivo ${ }^{21}$.

\section{Considerações Finais}

Espera-se que este pequeno artigo tenha conseguido mostrar aspectos relevantes da tradição jusnaturalista moderna que foram assimilados, rejeitados ou reinterpretados pelo filósofo de Frankfurt. Podem-se destacar (i) as características de universalidade, de imutabilidade, de parâmetro valorativo, e a validade em si e por si do direito natural como aspectos de concordância de Schopenhauer com a tradição moderna; (ii) a subsunção do conceito de direito à moral como um aspecto que, embora não seja original, pelo menos pode ser considerado subversivo frente à separação entre direito e moral vigente em sua época; (iii) o uso que Schopenhauer faz do direito natural para aludir ao direito internacional e ao direito de resistência.

\section{Referências}

BARRETO, V. Dicionário de filosofia do direito. (Organização Vicente de Paulo Barreto). São Leopoldo: Unisinos, Rio de Janeiro: Renovar, 2006.

BOBBIO, N. O Positivismo jurídico: lições de filosofia do direito. Compiladas por Nello Morra; tradução e notas Márcio Pugliesi, Edson Bini, Carlos E. Rodrigues. São Paulo: Ícone, 1995.

. Teoria da norma jurídica. Tradução Fernando Pavan Baptista e Ariani Bueno Sudatti; apresentação Alaôr Caffé Alves. Bauru: EDIPRO, 2001.

BOUCHER e KELLY. The social contract from Hobbes to Rawls. David Boucher, P. J. e Kelly (org). London; New York, N.Y.: Routledge, 1994.

BUCKLE, S. Natural law and the theory of property: Grotius to Hume. Oxford; New York: Clarendon Press: Oxford University Press, 1991.

CARTWRIGHT, D. Historical dictionary of Schopenhauer's philosophy. In: Historical dictionaries of religions, philosophies, and movements, $\mathrm{n}^{\circ}$. 55; Oxford: Scarecrow Press, 2005.

FASSÒ, G. Storia della filosofia del diritto, volume III: Ottocento e Novecento. Bolonha: Società editrice il Mulino, 1970. Pirámide S.A., 1979.

. Historia de la filosofia del derecho v. II, tradução de José F. Lorca Navarrete. Madri: Ediciones

${ }^{21}$ Cf. MVR II, cap. 47, p.651 (edição espanhola), p. 595 (edição inglesa), II 681. 
GODART-VAN DER KROON, A. Schopenhauer's theory of justice and its implication to natural law. in: Jahrbuch der Schopenhauer-Gesellschaft 2003. Band 84. Frankfurt am Main: Verlag Köningshausen \& Neuman Würzburg, 2003, p. 121-145.

GOYARD-FABRE, S. Os Fundamentos da Ordem Jurídica. São Paulo: Martins Fontes, 2002.

HAAKONSSEN, K. Natural law and moral philosophy: from Grotius to the Scottish enlightenment. Cambridge: Cambridge University Press, 1996.

Grotius, Pufendorf and modern natural law. In: The international library of critical essays in the history of philosophy. Co-autoria de Knud Haakonssen. Aldershot, Hants, Eng.; Brookfield, Vt.: Dartmouth: Ashgate, 1999.

HÖFFE, O. Estudios sobre teoria del derecho y la justiça; version castellana de Jorge M. Sena. Barcelona; Caracas: ALFA, 1988.

. Justiça política: fundamentação de uma filosofia critica do direito e do Estado; tradução: Ernildo Stein. Petrópolis, RJ: Vozes, 1991.

MORRIS, C.W. The social contract theorists: critical essays on Hobbes, Locke, and Rousseau. Organização de Christopher W Morris. Lanham, Md.: Rowman and Littlefield, 1999.

REALE, M. Filosofia do direito. São Paulo: Saraiva, 1999.

. Lições preliminares de direito. São Paulo: Saraiva, 2002.

SCHOPENHAUER, A. Arthur Schopenhauers sämtliche Werke; hrsg. Von Paul Deussen. Munique: R. Piper, 1911-1942.

SCHOPENHAUER, A. The world as will and representation, $2^{\circ}$ tomo; Tradução E.F.J. Payne. Nova York: Dover Publications, 1966.

. O mundo como vontade e como representação, $1^{\circ}$ tomo; Tradução, apresentação, notas e índices de Jair Barboza. São Paulo: Editora UNESP, 2005.

. El mundo como voluntad y representación, $2^{\circ}$ tomo (complementos); introdução, tradução e notas de Pilar López de Santa Maria. In: Coleção Clássicos de la cultura; Madri: Editorial Trotta SA, 2005.

TUCK, R. Natural rights theories: their origin and development. Cambridge: Cambridge University Press, 1981.

. Philosophy and government, 1572-1651. Cambridge: Cambridge University Press, 1993.

. The rights of war and peace - political thought and the international order from Grotius to Kant. New York: Oxford University Press, 1999.

Recebido: 20/06/11

Received: 06/20/11

Aprovado: 25/07/11

Approved: 07/25/11 